\title{
To Practice "Four-Integration" Talent Training Mode and Promote Deep Integration of Schools and Enterprises
}

\author{
Rui-Hua Wang \\ Liaoning Economic Vocational Technological Institute \\ Liaoning, China
}

\begin{abstract}
The Ministry of Education put forward "According to the characteristics of students in higher vocational colleges, we should cultivate students' social adaptability, educate students to establish the concept of lifelong learning, improve learning ability, communication and teamwork, enhance students' practical ability, creative ability, employability and entrepreneurship" in the document "Several Opinions on Comprehensively Improving the Teaching Quality of Higher Vocational Education". So the improvement of students' ability requires deep integration with enterprises in the talent cultivation mode. We should promote the cultural integration between the enterprise and the school, the study and career, the courses and positions, the classroom and workplace through establishing professional construction steering committee, holding lectures and workplace platforms, understanding of the internship and post-practice, introducing enterprises into the school, co-building factory school, school factory with enterprises and other ways. We should make both schools and enterprises cooperate in running school, education, employment and development to achieve the deep integration of the school and enterprise and better serve the regional, industrial economy and society.
\end{abstract}

Keywords-four-integration; talent training mode; schoolenterprise cooperation

\section{INTRODUCTION}

It is well known that talent training in higher vocational colleges depends on the continuous improvement and innovation of the talent training mode; the talent cultivation mode is the key factor of restricting talent cultivation in higher vocational colleges. With the progress and development of modern society, the demands of graduates are increasing for employers. If the vocational colleges train the graduates according to the traditional teaching methods, it will be hard to meet the needs of enterprises and institutions at the present stage. This requires vocational colleges to keep pace with the times, continue to reform the talent training mode according to the needs of the society and to meet the needs of society. We should strengthen the communication between school and industry enterprise, mobilize the industrial enterprises to run education and support education, train high-quality teachers, technical and skilled personnel, promote the transformation and application of technology through school-enterprise cooperative education. We should improve the quality of personnel training and the level of running a school; provide strong support for promoting the reform of school education and teaching and innovating the mode of personnel training.

\section{THE NECESSITY OF PRACTICING "FOUR- INTEGRATION" TALENT TRAINING MODE AND DEEP INTEGRATION OF SCHOOLS AND ENTERPRISES}

With the development of vocational education in China and the deep cooperation between vocational colleges and enterprises, it is particularly important for the students in vocational colleges to receive quality education and enterprise culture education. As we can see, the development direction of higher vocational colleges must extend to enterprises. You can't build a car behind closed doors, or cultivate students to be bookworms. We should train students to be qualified talents with an innovative spirit and creative ability. We need to bring enterprises into campus construction. The schoolenterprise cooperation training mode is embodied in the following four aspects:

The school and enterprise both have the intention to cooperate. On the one hand, enterprises need develop and schools not only need to train qualified technical and skilled personnel, but also need to improve the skills of their employees; on the other hand, the development of the school also needs to train talents with both theoretical and practical abilities through cooperation with enterprises. The two sides of the school and enterprise have mutual needs.

School -enterprise cooperation will produce scale and social effects. School-enterprise cooperation usually refers to cooperation between a schools' major or discipline and a group of enterprises or a certain industry. It will train a group of skilled talents, and solving the need for skilled personnel is not only the requirement for an enterprise but also for a group of enterprises or a certain industry, which enjoys a significant scale and social effect[1].

School-enterprise cooperation can improve the scale and efficiency of training skilled personnel. The implementation of school-enterprise cooperative training mode requires higher vocational colleges to have better training conditions inside and outside of the school. Students have theoretical and practical learning at school, and then go to the enterprise topractice. It is beneficial for students to master theoretical knowledge and professional skills quickly. This kind of training method, compared with the traditional model of 
master apprentice or enterprise's running technical school, is more efficient and effective.

School-enterprise cooperation is beneficial to improving the quality of personnel training. The process of schoolenterprise cooperation in the cultivation of skilled talents includes two links: the study of campus cultural knowledge and the cultivation of enterprise post ability. We should train the students in two completely different but mutually connected environments in and out of school. We should seamlessly connect theory teaching and practice teaching. It is also a deep reflection of the combination of education and productive labor[2]. Practice has proved that the students trained by this mode have a solid cultural and professional theoretical foundation. They not only have the professional skill that the job post needs, but also higher comprehensive quality and stronger ability to adapt to the society. They are deeply recognized by employer enterprises and society.

\section{THE WAY OF DEEP INTEGRATION BETWEEN HIGHER VOCATIONAL COLLEGES AND ENTERPRISES}

The cultural integration between colleges and enterprises: making use of the credit education in traditional culture to cultivate students' professional personality; making use of the foreign trade culture to cultivate students'distinct professional ability; corporating culture into the classroom will bring the advanced production and management philosophy, strict management system, advanced culture of safety procedures and management and others into the classroom and form a good professional atmosphere.

The integration of education and career: cultivating students' excellent professional skills, innovation and entrepreneurship; integrating school work with students' future career development through accurate position ability positioning.

The integration of courses and positions: based on the workflow, setting up the course system for the docking of courses and realize the integration of courses and posts. We make research on the requirements of occupational standards, knowledge, ability and quality in the post, so as to realize the corresponding supporting courses for the requirements of the post in the course system.

The integration of classroom and workplace: knowing the enterprise through the foreign trade understanding internship in the first term. Through the training site of the international trade experience base, the training room is integrated into the workplace environment in the second term. We train courses to enterprises, so students know the standards of professional posts in the third and fourth term. Through the post internship, students know the corporate culture and professional norms; finally completing the integration of classroom and workplace in the fifth and sixth term.

\section{THE METHODS AND MODES OF DEEP INTEGRATION BETWEEN HIGHER VOCATIONAL COLLEGES AND ENTERPRISES}

With the platform of professional construction committee and school association cooperation committee, through the establishment of expert studio, teacher workstation and other measures, we build a barrier-free cultural exchange platform between schools and enterprises, introduce the excellent consciousness of innovation, competition, responsibility, dedication, craftsmanship and team spirit in the enterprise culture into the construction of campus culture, integrate them into the constructions of school spirit and study spirit, form a good vocational education atmosphere, hence helping students establish a correct professional concept and develop good professional habits[3].

Through holding lectures, workplace lectures, understanding of the internship and post-practice, we can let students know the enterprise and have a more intuitive understanding of their responsibility and the mission to become "enterprise people' in the future. In addition, in the atmosphere, teachers will also feel the influence of corporate culture and collect first-hand materials and cases, which will be helpful for them to integrate the corporate culture elements into the teaching content in the subsequent classroom teaching process and carry out targeted enlightenment guidance.

We should bring enterprises into the campus, such as the cooperation with SF Express (Shenyang) co., LTD, to strengthen the integration of school-enterprise culture. We set up SF order classes, "Order class" enables students to learn and practice in a real workplace environment, deepen the cooperation between associations and enterprises in the same industry. Through the co-construction of off-campus practice teaching base, students play the dual roles of "on-campus students" and "prospective employees" to improve students' professional quality and practical work ability in the real working environment. We realize the connection between "school and enterprise”, "learning and employment” and "zero distance”.

We build "factory school, school factory" with enterprises. For example, we cultivate talents with Shenyang Jingdong century trade co. LTD. The school has set up teachers' workstations in Jingdong enterprises to provide teachers with practical training positions and improve their practical teaching ability. We recommend Jingdong group technical backbone, model workers as part-time teachers. From the perspective of enterprises, we put forward the specification and ability requirement of the cultivation of high-quality skilled talents and formulate the evaluation mechanism. We provide students with internship, post-internship, postinternship site and related resources, and provide labor security. In the first term, students will visit Jingdong. Jingdong enterprises go to the school to give the workplace lecture, let the students feel the corporate culture atmosphere, know the professional positions. Students realize the cultural integration of schools and enterprises, have the practice with post in the second, third and fourth term. Students need to pass the position assessment of Jingdong and will be evaluated by the enterprise in their internship. After the internship, we held a summary commendation meeting or class meeting to summarize the skills and professionalism of the position. It realizes the integration of curriculum and post skills, classroom and workplace. In the fifth and sixth term, students will go to Jingdong to have post practice. Enterprises will select outstanding students to become employees. It realizes the integration of study and career. 


\section{REFERENCES}

From what has been discussed above, we can see that through school-enterprise cooperative education, we can strengthen the communication between schools and industrial enterprises, mobilize industrial enterprises in education and education support, training high-quality teachers and technical and skilled personnel, promote the transformation and application of technology. We should improve the quality of personnel training and the level of running a school fundamentally, and provide strong support for promoting the reform of school education and teaching and innovating the mode of personnel training. Schools and enterprises should take the initiative to adapt to the needs of regional and industrial economic and social development, explore the new modes of school-enterprise cooperation and personnel training, make school and enterprise cooperate in "running school, education, employment and development" to realize the "deep integration of school and enterprise”, hence better serving the regional, industrial economy and society.
[1] Tang Xiaofeng. The Exploration and Practice of the Talent Training Mode of 'School-Enterprise Cooperation and combining Work with Study’, 2019.

[2] Gao Jun, Zhu Shuhui, Gui Guorong. The Analysis on Effective Path of Innovative Talents Training under Collaborative Innovation Mechanism [J].The Journal of Heihe River, 2016(05).

[3] Gu Linsen. The Practice Research on School-Enterprise Cooperation, Combination of Work and Study, and Four-stage Progressive Talent Training Mode[J].Modern Vocational Education. Vocational Training, 2015(06).

[4] Liu Gang. Innovation and Practice of Working Mode of Middle School Students in School Enterprise “Two Subjects” Cooperation School [J]. Guide to Knowledge, 2017

[5] Zhang Lihui, Wang Rui, Wei Liming. Innovation and Exploration of Talent Training Mode of School Enterprise Cooperation in Higher Vocational Education [J]. Education Observation, 2016, 0 (7).

[6] Cheng Liang. Research on the Mode of Cooperation Between Universities and Enterprises in the Regional Economy [J]. Journal of Hebei University of Engineering: Social Sciences, 2016, 33 (4). 